\title{
Supplementary Information for Liquid chromatography-tandem mass spectrometry to determine sedative hypnotic drugs in river water and wastewater
}

Paula Arbeláez, Francesc Borrull, Eva Pocurull*, Rosa Maria Marcé Department of Analytical Chemistry and Organic Chemistry Universitat Rovira i Virgili, Tarragona 43007, Spain

* Corresponding author. Email: eva.pocurull@urv.cat 
Table S1. SRM conditions. Quantifier and confirmation ions for determination of benzodiazepines and barbiturates.

\begin{tabular}{cccccccccc}
\hline & & \multicolumn{1}{c}{ Product ions } & Cone \\
\cline { 3 - 9 } Compound & $\begin{array}{c}\text { Precursor } \\
\text { ion }\end{array}$ & \multicolumn{1}{c}{ Quantifier } & \multicolumn{1}{c}{ Confirmation 1 } & Confirmation 2 & Voltage (V) \\
\hline Barbital (BTL) & 183 & 140 & $(5)$ & 42 & $(15)$ & & & 90 \\
Phenobarbital (PNB) & 231 & 42 & $(9)$ & 188 & $(6)$ & & & 90 \\
Bromazepam (BMZ) & 316 & 182 & $(35)$ & 209 & $(25)$ & 288 & $(18)$ & 140 \\
Carbamazepine (CBZ) & 237 & 194 & $(15)$ & 179 & $(35)$ & & & 120 \\
Pentobarbital (PTB) & 225 & 182 & $(7)$ & 42 & $(14)$ & & & 100 \\
Secobarbital (SCB) & 237 & 194 & $(6)$ & 42 & $(14)$ & & & 90 \\
Diazepam (DZP) & 285 & 193 & $(35)$ & 222 & $(27)$ & 154 & $(25)$ & 150 \\
Nordiazepam (NDZ) & 271 & 140 & $(25)$ & 165 & $(30)$ & 208 & $(30)$ & 150 \\
\hline \hline
\end{tabular}

Collision Energy (eV) in brackets

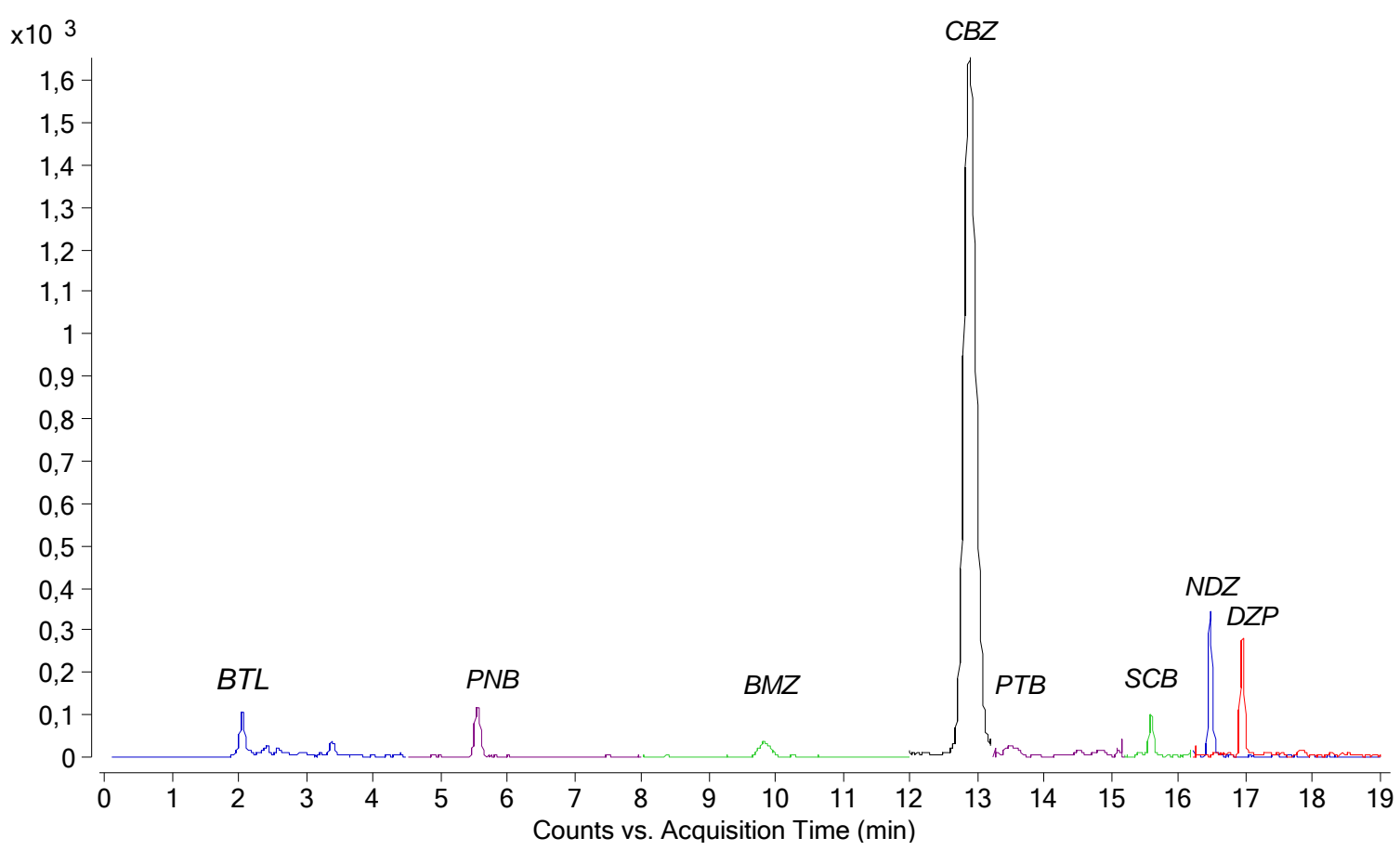

Figure S1. Chromatographic separation

Figure S1 shows the chromatographic separation in influent sample spiked at $250 \mathrm{ng} / \mathrm{L}$ for barbiturates and $25 \mathrm{ng} / \mathrm{L}$ for benzodiazepines. For the rest of the chromatographic conditions see the manuscript section 2.4. 


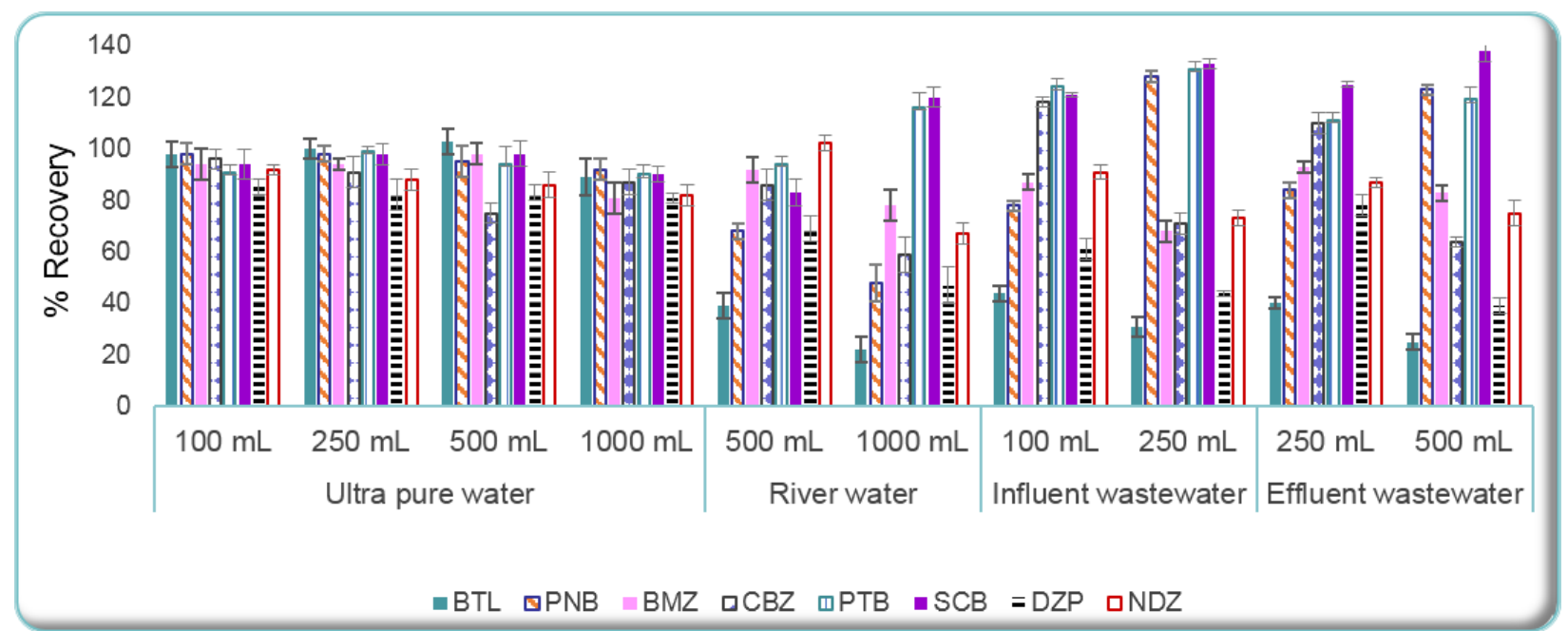

Figure S2. Breakthrough volume in the different matrices 